\title{
Does Cardiopulmonary Testing Help Predict Long-Term Survival After Esophagectomy?
}

\author{
Jakub Chmelo, MUDr, MRCSEd ${ }^{1}$, Rachel A. Khaw, MRes, MBChB ${ }^{1}$, Rhona C. F. Sinclair, BMedSci, BMBS, \\ MPhil, MRCP, FRCA ${ }^{2}$, Maziar Navidi, MBChB, MD, FRCSEd ${ }^{1}$, and Alexander W. Phillips, MD, MA, FRCSEd, \\ FFSTEd $^{1,3}$
}

${ }^{1}$ Northern Oesophagogastric Unit, Royal Victoria Infirmary, Newcastle Upon Tyne, UK; ${ }^{2}$ Department of Anaesthesia and Critical Care Medicine, Royal Victoria Infirmary, Newcastle Upon Tyne, UK; ${ }^{3}$ School of Medical Education, Newcastle University, Newcastle Upon Tyne, UK

\begin{abstract}
Background. Esophagectomy is associated with a high rate of morbidity and mortality. Preoperative cardiopulmonary fitness has been correlated with outcomes of major surgery. Variables derived from cardiopulmonary exercise testing (CPET) have been associated with postoperative outcomes. It is unclear whether preoperative cardiorespiratory fitness of patients undergoing esophagectomy is associated with long-term survival. This study aimed to evaluate whether any of the CPET variables routinely derived from patients with esophageal cancer may aid in predicting long-term survival after esophagectomy.

Methods. Patients undergoing CPET followed by transthoracic esophagectomy for esophageal cancer with curative intent between January 2013 and January 2017 from single high-volume center were retrospectively analyzed. The relationship between predictive co-variables, including CPET variables and survival, was studied with a Cox proportional hazard model. Receiver operation curve (ROC) analysis was performed to find cutoff values for CPET variables predictive of 3-year survival.

Results. The study analyzed 313 patients. The ventilatory equivalent for carbon dioxide $\left(\mathrm{VE} / \mathrm{VCO}_{2}\right)$ at the anerobic threshold was the only CPET variable independently predictive of long-term survival in the multivariable analysis
\end{abstract}

(C) The Author(s) 2021

First Received: 17 March 2021

Accepted: 21 April 2021;

Published Online: 26 May 2021

A. W. Phillips, MD, MA, FRCSEd, FFSTEd

e-mail: awphillips@doctors.net.uk (hazard ratio [HR], 1.049; 95\% confidence interval [CI], 1.011-1.088; $p=0.011$ ). Pathologic stages 3 and 4 disease was the other co-variable found to be independently predictive of survival. An ROC analysis of the $\mathrm{VE} / \mathrm{VCO}_{2}$ failed to demonstrate a predictive cutoff value of 3-year survival (area under the curve, 0.564; 95\% CI, 0.499-0.629; $p=0.056$ ).

Conclusions. A high $\mathrm{VE} / \mathrm{VCO}_{2}$ before esophagectomy for malignant disease is an independent predictor of long-term survival and may be an important variable for clinicians to consider when counseling patients.

Esophagectomy, the cornerstone for curative treatment of patients with esophageal cancer, ${ }^{1}$ is associated with high rates of morbidity and mortality $(2.1 \%){ }^{2}$ Preoperative cardiopulmonary fitness has been correlated with outcomes in various types of surgery. These have indicated that less fit patients have a higher incidence of postoperative morbidity and mortality. ${ }^{3,4}$

Many centers use cardiopulmonary exercise testing as a method of individualized risk assessment before major surgery. Severe complications in the postoperative period after esophagectomy may reduce long-term survival. ${ }^{5}$ Variables derived from cardiopulmonary exercise testing (CPET) such as the anaerobic threshold and peak oxygen uptake $\left(\mathrm{VO}_{2 \text { peak }}\right)$ have been associated with an increased chance of complications developing after esophagogastric cancer surgery, although study results are conflicting. ${ }^{6-17}$

It is unclear whether the preoperative cardiorespiratory fitness of patients undergoing esophagectomy is associated with intermediate or long-term survival. This study aimed 
to evaluate whether any of the CPET variables routinely derived in patients with esophageal cancer may aid in predicting long-term survival after esophagectomy.

\section{METHODS}

\section{Patient Population}

A contemporaneously maintained database of all patients with adenocarcinoma or squamous cell carcinoma of the esophagus or gastroesophageal junction was reviewed. The study investigated patients undergoing esophagectomy for esophageal cancer with curative intent between January 2013 and January 2017 at the Northern Oesophagogastric Unit, Newcastle upon Tyne. Previous studies have evaluated the association of CPET variables and perioperative morbidity, but the main aim of this study was to investigate the association of these variables with long-term survival. To this end, patients who died within 30 days after surgery were excluded from survival calculations.

\section{Staging and Treatment}

Initial cancer staging comprised endoscopy with biopsy, endoscopic ultrasonography, and a thoraco-abdominal computed tomography scan and positron emission tomography. Operative fitness was assessed using cardiopulmonary exercise testing. ${ }^{18,19}$ Patients with locally advanced tumors ( $\geq \mathrm{T} 3$, any node-positive disease) were considered for perioperative chemotherapy with $\mathrm{ECX}^{20}$ or neoadjuvant chemoradiation therapy using the CROSS protocol. $^{21}$ Current Union for International Cancer Control TNM 8 was used to stage all the patients in this study. Comorbidities were scored using the Charlson Comorbidity Index. $^{22,23}$

The majority of the resections were performed using a standardized two-phase transthoracic approach (Ivor Lewis) with a radical en bloc abdominal and mediastinal lymphadenectomy as previously described. ${ }^{24}$ A small number of patients had a three-stage procedure with neck anastomosis, and a single patient was treated with a left thoraco-abdominal approach (Table 1). For the majority of the patients, this was performed as an open procedure, but a small number of patients had a thoracoscopic chest phase with an equivalent lymphadenectomy.

All the patients were managed in the perioperative period with an enhanced recovery after surgery program (ERAS). After discharge from the hospital, the patients were routinely followed up in the outpatient clinic. Followup reviews were initially performed in 3- to 6-month intervals during the first 2 years and annually thereafter unless clinical factors determined a more frequent followup evaluation. Patient mortality was recorded from the hospital electronical system or the general practitioner record on 14 July 2020, providing a minimum follow-up interval of 42 months.

\section{Cardiopulmonary Exercise Testing}

At the Northern Oesophagogastric Unit (NOGU), CPET has been used to assess patients potentially undergoing esophagectomy since January 2013. This test forms part of the initial assessment, and the results are used to assist in the tumor board treatment decisions. All the patients in this study had completed at least 3 years of follow-up evaluation since surgery. The patients' CPET data, demographics, and information relating to their disease, operation, postoperative period, and survival were analyzed.

In this study, CPET was performed in accordance with the American Thoracic Society/American College of Chest Physicians guidelines for this testing. ${ }^{19}$ These guidelines also were used to exclude patients who had a contraindication to undergoing CPET. Each test was performed according to a local protocol based on that described by Older et al. ${ }^{3}$ The patients performed a continuous pedaling ramped test on a cycle ergometer (Ergoselect 200, Ergoline GmbH, Bitz, Germany) until they were physically exhausted, had reached $\mathrm{VO}_{2 \max }$, or had to discontinue the test due to clinical indications.

A standard 12-lead electrocardiogram (ECG) with ST segment analysis together with pulse oximetry (Welch Allyn, Skaneateles Falls, New York, NY, USA) was used throughout the test. Metabolic gas analysis was performed via the metabolic cart (Ultima Series; MGC Diagnostics, Saint Paul, MN, USA). The CPET data were analyzed using the Breeze SuiteTM software (Ultima Series; MGC Diagnostics). The tests were reported by a consultant anesthetist trained in reporting CPET.

The $\mathrm{VO}_{2 \text { peak }}$ was defined as the highest oxygen consumption recorded at volitional exhaustion during the last $30 \mathrm{~s}$ of the exercise. The anaerobic threshold was defined by the $\mathrm{V}$-slope method representing the amount of $\mathrm{VO}_{2}$ during a ramped test above which aerobic energy production is supplemented by anaerobic mechanisms. ${ }^{25}$ The ventilatory equivalents of carbon dioxide $\left(\mathrm{VE} / \mathrm{VCO}_{2}\right)$ were determined using linear regression analysis of $\mathrm{VE}$ and $\mathrm{VCO}_{2}$ at the anaerobic threshold level. ${ }^{26}$ If the anaerobic threshold was not reached, $\mathrm{VE} / \mathrm{VCO}_{2}$ was recorded as the lowest value observed.

\section{Statistical Analysis}

Statistical analysis was performed using IBM SPSS Statistics version 26 (IBM, Armonk, USA). A 
TABLE 1 Demographics of the patients ${ }^{\mathrm{a}}$

\begin{tabular}{|c|c|c|}
\hline Median age at operation: years (IQR) & & $66(60-71)$ \\
\hline Gender, male & & $236(75.4)$ \\
\hline \multirow[t]{3}{*}{ ASA } & 1 & $22(7.0)$ \\
\hline & 2 & $183(58.5)$ \\
\hline & 3 & $108(34.5)$ \\
\hline Median VE/VCO 2 (IQR) & & $29(27-32)$ \\
\hline Median AT: $\mathrm{ml} \mathrm{min}^{-1} \mathrm{~kg}^{-1}$ (IQR) & & $14.1(12.2-17.3)$ \\
\hline Median $\mathrm{VO}_{2 \text { peak }}: \mathrm{ml} \mathrm{min}{ }^{-1} \mathrm{~kg}^{-1}$ (IQR) & & $19.2(16.2-22.7)$ \\
\hline Median CCI: $n$ (IQR) & & $4(4-5)$ \\
\hline Histology, AC & & $232(74.1)$ \\
\hline Neoadjuvant treatment, yes & & $232(74.1)$ \\
\hline \multirow[t]{3}{*}{ Operation type } & Ivor Lewis & $292(93.3)$ \\
\hline & McKeown & $20(6.4)$ \\
\hline & Left thoraco-abdominal & $1(0.3)$ \\
\hline \multirow[t]{5}{*}{ Pathologic stage } & 0 & $27(8.6)$ \\
\hline & 1 & $61(19.5)$ \\
\hline & 2 & $74(23.6)$ \\
\hline & 3 & $113(36.1)$ \\
\hline & 4 & $38(12.1)$ \\
\hline \multirow[t]{6}{*}{ Tumor regression grade } & 1 & $27(8.6)$ \\
\hline & 2 & $18(5.8)$ \\
\hline & 3 & $62(19.8)$ \\
\hline & 4 & $100(31.9)$ \\
\hline & 5 & $21(6.7)$ \\
\hline & Unknown & $85(27.2)$ \\
\hline Longitudinal resection margin, $\mathrm{R} 1$ & & $8(2.6)$ \\
\hline
\end{tabular}

$I Q R$ interquartile range, ASA American Society of Anesthesiologists physical status classification system, $V E / V C \mathrm{O}_{2}$ ventilatory equivalents of carbon dioxide, $A T$ anaerobic threshold, $\mathrm{VO}_{2 \text { peak }}$ peak oxygen uptake, $C C I$ Charlson Comorbidity Index, $A C$ adenocarcinoma

${ }^{\mathrm{a}}$ Values in parenthesis are percentages unless indicated otherwise. multivariable Cox regression model was used to establish the relationship between predictive variables and survival. Variables with a $p$ value lower than 0.1 in the univariable analysis were inserted into the model. Survival was estimated using Kaplan-Meier survival curves and compared using the log-rank test. Receiver operation curve (ROC) analysis was conducted for CPET variables that were independently predictive of survival in the Cox regression model. Survival status at 3 years was used as a dependent binary variable in the ROC analysis. A $p$ value lower than 0.05 was deemed statistically significant.

\section{RESULTS}

During the study period, 318 patients underwent esophagectomy with curative intent. Five patients were excluded due to death within the first 30 days after surgery. The remaining 313 patients were analyzed in this study. Of these 313 patients, $236(75.4 \%)$ were male, and the median age was 66 years (range, $42-84$ years). The majority of the patients received neoadjuvant treatment (74.1\%). The characteristics for the entire cohort are shown in Table 1.

The median survival time was 57 months. The factors found to be predictive of survival in the univariable analysis are listed in the Table 2.

In the univariable analysis, the $\mathrm{VE} / \mathrm{VCO}_{2}$ at the anaerobic threshold was the only CPET variable significantly predictive of survival (hazard ratio [HR], 1.054; 95\% confidence interval $[\mathrm{CI}], 1.017-1.093 ; p=0.004)$. The anaerobic threshold (HR, 0.991; 95\% CI, 0.955-1.029; $p=$ $0.635)$ and $\mathrm{VO}_{2 \text { peak }}(\mathrm{HR}, 0.987 ; 95 \% \mathrm{CI}, 0.957-1.017 ; p=$ $0.391)$ were not found to be associated with survival.

The multivariable analysis showed that $\mathrm{VE} / \mathrm{VCO}_{2}(\mathrm{HR}$, 1.049; 95\% CI, 1.011-1.088; $p=0.011$ ) is a significant independent predictor of overall survival. In the multivariable model, pathologic stages 3 and 4 disease was the other co-variable found to be independently predictive of survival (Table 3). 
TABLE 2 Cox univariable regression analysis of the factors influencing survival ${ }^{\mathrm{a}}$

\begin{tabular}{|c|c|c|c|}
\hline & HR & $95 \% \mathrm{CI}$ & $p$ Value \\
\hline Male gender & 1.424 & $0.961-2.111$ & 0.078 \\
\hline $\mathrm{CCI}$ & 1.192 & $1.039-1.367$ & 0.012 \\
\hline Neoadjuvant treatment, yes & 1.278 & $0.878-1.860$ & 0.201 \\
\hline Age at operation & 1.015 & $0.995-1.035$ & 0.150 \\
\hline ASA 1 & Reference & & \\
\hline 2 & 1.247 & $0.649-2.398$ & 0.508 \\
\hline 3 & 1.424 & $0.728-2.788$ & 0.302 \\
\hline $\mathrm{VE} / \mathrm{VCO}_{2}$ & 1.054 & 1.017-1.093 & 0.004 \\
\hline AT & 0.991 & $0.955-1.029$ & 0.635 \\
\hline $\mathrm{VO}_{2 \text { peak }}$ & 0.987 & $0.957-1.017$ & 0.391 \\
\hline Histology, AC & 1.572 & $1.061-2.329$ & 0.024 \\
\hline Longitudinal resection margin, $\mathrm{R} 1$ & 2.623 & 1.154-5.959 & 0.021 \\
\hline Pathologic stage 0 & Reference & & \\
\hline 1 & 0.577 & $0.205-1.620$ & 0.494 \\
\hline 2 & 1.277 & $0.518-3.150$ & 0.467 \\
\hline 3 & 5.351 & 2.331-12.285 & $<\mathbf{0 . 0 0 1}$ \\
\hline 4 & 10.518 & $4.399-25.150$ & $<\mathbf{0 . 0 0 1}$ \\
\hline Tumor regression grade 1 & Reference & & \\
\hline 2 & 1.152 & $0.351-3.774$ & 0.816 \\
\hline 3 & 1.490 & $0.601-3.692$ & 0.389 \\
\hline 4 & 4.403 & $1.911-10.143$ & $<\mathbf{0 . 0 0 1}$ \\
\hline 5 & 5.310 & 2.091-13.489 & $<\mathbf{0 . 0 0 1}$ \\
\hline Unknown & 2.280 & $0.964-5.394$ & 0.061 \\
\hline Clavien-Dindo complications grade None & Reference & & \\
\hline $1-2$ & 0.924 & $0.647-1.319$ & 0.662 \\
\hline $3-4$ & 1.378 & $0.853-2.225$ & 0.190 \\
\hline
\end{tabular}

The survival curves indicated shorter survival with higher $\mathrm{VE} / \mathrm{VCO}_{2}$ when the patients were stratified into groups according to their $\mathrm{VE} / \mathrm{VCO}_{2}$ value (Fig. 1). The median survival time was not reached for the group with a $\mathrm{VE} / \mathrm{VCO}_{2}$ lower than 26 or for the group with a $\mathrm{VE} / \mathrm{VCO}_{2}$ of 26 to 30. It was 46 months for the group with a VE/ $\mathrm{VCO}_{2}$ of 31 to 35 and 29 months for the group with a VE/ $\mathrm{VCO}_{2}$ higher than 35 . The difference between the groups was found to be statistically significant $(p=0.015)$.

The ROC analysis of $\mathrm{VE} / \mathrm{VCO}_{2}$ failed to demonstrate a predictive cutoff value that would divide patients into groups with a low or high chance of a 3-year survival period (area under the curve [AUC], 0.564; 95\% CI, $0.499-0.629 ; p=0.056$ ).

\section{DISCUSSION}

The results from this study indicate that ventilatory inefficiency (high $\mathrm{VE} / \mathrm{VCO}_{2}$ ) is associated with long-term survival for patients undergoing esophagectomy for malignant disease. The overall 30 -day mortality rate was $1.9 \%$, and the 90 -day mortality rate was $3.1 \%$. When patients are stratified according to their $\mathrm{VE} / \mathrm{VCO}_{2}$, a clear association of higher (poorer) $\mathrm{VE} / \mathrm{VCO}_{2}$ is observed, with worse long-term survival.

Previously, $\mathrm{VE} / \mathrm{VCO}_{2}$ was linked with pulmonary morbidity after lung resection ${ }^{27}$ and abdominal aortic repair surgery. ${ }^{28}$ However, the data for patients undergoing esophagectomy is sparse despite the high morbidity and physiologic demand of this procedure on a patient's reserve. These results are similar to the findings of Wilson et al., ${ }^{29}$ who examined 1375 patients undergoing colorectal cancer surgery and demonstrated that $\mathrm{VE} / \mathrm{VCO}_{2}$ was 
TABLE 3 Cox multivariable regression analysis of the factors influencing survival ${ }^{\mathrm{a}}$

\begin{tabular}{llll}
\hline & HR & $95 \%$ CI & $p$ Value \\
\hline Male gender & 1.511 & $0.985-2.319$ & 0.059 \\
$\mathrm{CCI}$ & 1.138 & $0.985-1.313$ & 0.078 \\
$\mathrm{VE} / \mathrm{VCO}_{2}$ & $\mathbf{1 . 0 4 9}$ & $\mathbf{1 . 0 1 1 - 1 . 0 8 8}$ & $\mathbf{0 . 0 1 1}$ \\
Histology, AC & 1.444 & $0.939-2.220$ & 0.094 \\
Longitudinal resection margin, R1 & 0.725 & $0.307-1.716$ & 0.465 \\
Pathologic stage 0 & Reference & & \\
1 & 0.594 & $0.079-4.490$ & 0.614 \\
2 & 1.842 & $0.266-12.778$ & 0.536 \\
$\mathbf{3}$ & $\mathbf{7 . 5 4 5}$ & $\mathbf{1 . 0 7 0 - 5 3 . 1 8 8}$ & $\mathbf{0 . 0 4 3}$ \\
$\mathbf{4}$ & $\mathbf{1 5 . 1 7 2}$ & $\mathbf{2 . 1 0 0 - 1 0 9 . 6 0 0}$ & $\mathbf{0 . 0 0 7}$ \\
Tumor regression grade 1 & Reference & & \\
2 & 0.342 & $0.041-2.876$ & 0.323 \\
3 & 0.352 & $0.048-2.595$ & 0.306 \\
4 & 0.632 & $0.088-4.528$ & 0.648 \\
5 & 0.639 & $0.084-4.861$ & 0.665 \\
Unknown & 0.831 & $0.120-5.755$ & 0.851 \\
\hline
\end{tabular}

$\mathrm{HR}$ hazard ratio, $\mathrm{CI}$ confidence interval, $\mathrm{CCI}$ Charlson Comorbidity Index, $\mathrm{VE} / \mathrm{VCO}_{2}$ ventilatory equivalents of carbon dioxide, $A C$ adenocarcinoma

${ }^{\mathrm{a}}$ Bold indicates significant findings.

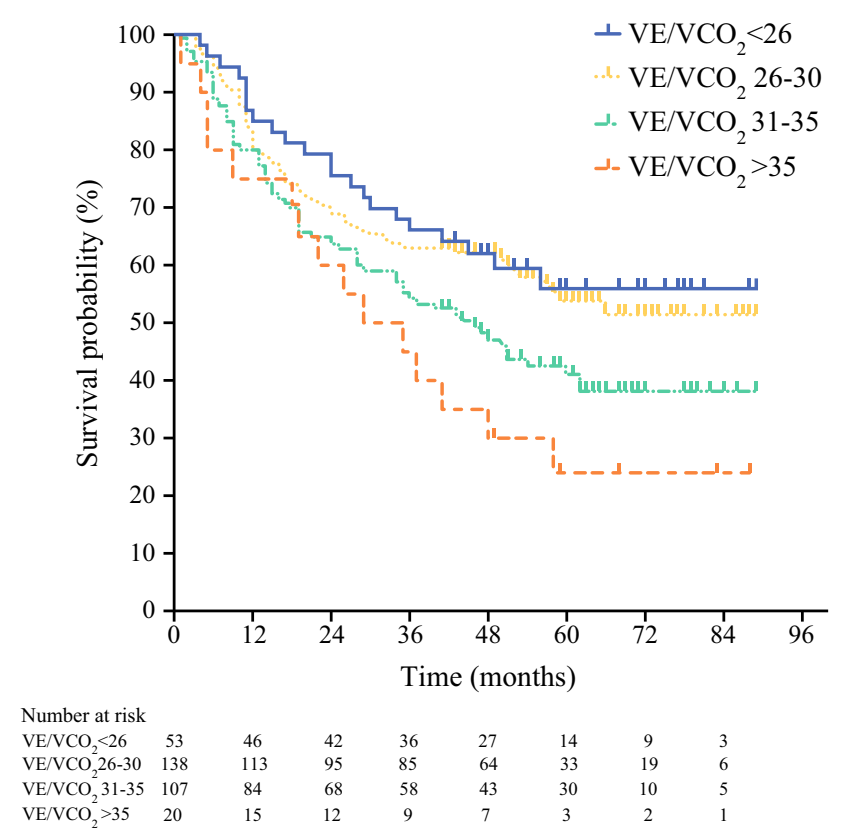

FIG. 1 Kaplan-Meier curves showing survival according to VE/ $\mathrm{VCO}_{2}$

independently associated with 90-day mortality and longterm survival. Apart from the evidence of spread during the surgery (indicating metastatic disease), this study of colorectal patients did not consider other oncologic factors that might influence long-term survival. Importantly, in the current study, after adjustment for several oncologic factors (neoadjuvant therapy, pathologic stage of the disease, resection margin involvement, and tumor regression grade), $\mathrm{VE} / \mathrm{VCO}_{2}$ remained an independent predictor of survival. In addition, the comorbidities of the patients were considered, and when the Charlson Comorbidity Index was used to adjust for these comorbidities, they were not found to be associated with overall survival. The reasons for this may be that a minimum yet sufficient level of fitness must exist before a patient is considered for esophagectomy, with less fit patients commonly excluded from surgery.

The results of this study confirm that a high $\mathrm{VE} / \mathrm{VCO}_{2}$ should remain a trigger for further detailed investigations of an individual's health before esophagectomy. An elevated $\mathrm{VE} / \mathrm{VCO}_{2}$ should prompt consideration of asymptomatic heart failure, chronic obstructive pulmonary disease (COPD), or interstitial pulmonary disease. In the current cohort, only one patient had presented with a clinical diagnosis of heart failure, but by CPET criteria, other patients had CPET-defined "heart failure." Patients with a diagnosis of heart failure usually are not deemed sufficiently fit to undergo esophagectomy without being optimized. Therefore, $\mathrm{VE} / \mathrm{VCO}_{2}$ can be used to stratify patients into low- and high-risk categories and may potentially identify a group that can be optimized before surgery.

Patients with poor cardiopulmonary function have less physiologic reserve and are less able to cope with postoperative complications. The literature contains conflicting results as to whether complications after esophagogastric surgery lead to poorer long-term survival. ${ }^{30-32}$ In the 
current study, severe complications, defined as ClavienDindo grade 3 or higher, within 30 days after surgery were not related to survival in the univariable analysis.

Interestingly, these data did not demonstrate any association of survival with other commonly reported CPET variables such as the anaerobic threshold $(p=0.635)$ or $\mathrm{VO}_{2 \text { peak }}(p=0.391)$. The findings are conflicting concerning the use of CPET variables for prediction of postoperative mortality after esophagogastric surgery. Both Whibley et al. ${ }^{12}$ and Benington et al. ${ }^{15}$ demonstrated an association between the anaerobic threshold, $\mathrm{VO}_{2 \text { peak }}$, and mortality after esophagogastric resections. Jack et al. ${ }^{33}$ found this association only for the pre-neoadjuvant chemotherapy anaerobic threshold. These studies had smaller samples than the current analysis, concentrated mainly on early mortality, demonstrated association with univariable analyses, or used dichotomized rather than continuous variables, which can lead to misleading results. ${ }^{34}$ In contrast, Patel et al. ${ }^{16}$ did not demonstrate any association between these variables and mortality. The failure of the anaerobic threshold and the $\mathrm{VO}_{2 \text { peak }}$ to reach significance in the current study might have been due to the higher baseline values of these parameters. The median anaerobic threshold of $14.1 \mathrm{ml} / \mathrm{min}^{-1} / \mathrm{kg}^{-1}$ and the $\mathrm{VO}_{2 \text { peak }}$ of $19.2 \mathrm{ml} / \mathrm{min}^{-1} / \mathrm{kg}^{-1}$ rendered this cohort more fit than the cohorts in some other studies. This study also aimed to investigate long-term survival. The anaerobic threshold and the $\mathrm{VO}_{2 \text { peak }}$ are commonly associated with poor perioperative outcomes for patients after major surgery. ${ }^{4}$ The pathologic stage of the disease is one of the strongest predictors of survival in esophageal cancer. The findings regarding $\mathrm{VE} / \mathrm{VCO}_{2}$ are relevant for patient counseling because they identify another factor that could help to inform clinicians and patients on long-term prognosis. Although the ROC analysis did not determine a predictive cutoff for identifying higher-risk patients, a clear trend emerged when the patients were stratified according to the $\mathrm{VE} / \mathrm{VCO}_{2}$. For the patients with a $\mathrm{VE} / \mathrm{VCO}_{2}$ higher than 35 , the median survival time was 29 months compared with 46 months for those with a VE/ $/ \mathrm{VCO}_{2}$ of 31 to 35 . Therefore, different and less aggressive treatment options that maintain higher post-treatment quality of life might be sought for patients with ventilatory inefficiency.

This study had a number of limitations. It was a retrospective study with its inherent limitations. However, the data were collected contemporaneously. Although this was the largest study to assess CPET variables in esophageal cancer surgery, it was not possible to identify cutoff values of $\mathrm{VE} / \mathrm{VCO}_{2}$ suggesting which patients are more likely to survive for 3 years. Furthermore, no data exist to show the patients who might have been excluded based on their CPET results. It is expected that many patients with ventilatory inefficiency never progressed to surgery. Although neoadjuvant treatment leads to longer overall survival, ${ }^{20},{ }^{21}$ some patients who have become deconditioned during chemotherapy ${ }^{35}$ might actually survive for a shorter period as a result. The CPET data analyzed in this study were measured before any oncologic treatment. Thus, these values did not account for the impact of neoadjuvant chemotherapy treatment on cardiopulmonary fitness. However, previous findings have demonstrated that VE/ $\mathrm{VCO}_{2}$ remains unchanged during the neoadjuvant part of the treatment. ${ }^{35}$

The study deliberately excluded patients who died within 30 days after surgery because the focus was on longterm survival. However, the study chose to include the patients who died within 90 days. There were two main reasons for this. First, it was thought that these patients may have died due to postoperative complications they struggled to overcome because of a worse baseline fitness instead of a more sudden acute complication. Second, those with a short survival not curtailed by complications conceivably could have died within this time frame.

Controversy remains within the available published literature surrounding CPET variables and outcome prediction. More studies with larger samples are needed to investigate this for further improvement in the clinical utility of CPET before esophageal surgery.

However, the large cohort of patients that underwent esophageal surgery in the current study demonstrated that $\mathrm{VE} / \mathrm{VCO}_{2}$ does have a role in prognostication.

\section{DISCLOSURE There are no conflicts of interest.}

OPEN ACCESS This article is licensed under a Creative Commons Attribution 4.0 International License, which permits use, sharing, adaptation, distribution and reproduction in any medium or format, as long as you give appropriate credit to the original author(s) and the source, provide a link to the Creative Commons licence, and indicate if changes were made. The images or other third party material in this article are included in the article's Creative Commons licence, unless indicated otherwise in a credit line to the material. If material is not included in the article's Creative Commons licence and your intended use is not permitted by statutory regulation or exceeds the permitted use, you will need to obtain permission directly from the copyright holder. To view a copy of this licence, visit http://creativecommons. org/licenses/by/4.0/.

\section{REFERENCES}

1. Griffin SM, Jones R, Kamarajah SK, et al. Evolution of esophagectomy for cancer over years: changes in presentation, management, and outcomes. Ann Surg Oncol. 2020;28:3011-22.

2. National Oesophago-Gastric Cancer Audit 2019. 2019.

3. Older P, Smith R, Courtney P, Hone R. Preoperative evaluation of cardiac failure and ischemia in elderly patients by cardiopulmonary exercise testing. Chest. 1993;104:701-4.

4. Moran J, Wilson F, Guinan E, McCormick P, Hussey J, Moriarty $\mathrm{J}$. Role of cardiopulmonary exercise testing as a risk-assessment 
method in patients undergoing intra-abdominal surgery: a systematic review. Br J Anaesth. 2016;116:177-91.

5. Markar S, Gronnier C, Duhamel A, et al. The impact of severe anastomotic leak on long-term survival and cancer recurrence after surgical resection for esophageal malignancy. Ann Surg. 2015;262:972-80.

6. Liedman BL, Bennegård K, Olbe LC, Lundell LR. Predictors of postoperative morbidity and mortality after surgery for gastrooesophageal carcinomas. Eur J Surg. 1995;161:173-80.

7. Liedman B, Johnsson E, Merke C, Ruth M, Lundell L. Preoperative adjuvant radiochemotherapy may increase the risk in patients undergoing thoracoabdominal esophageal resections. Dig Surg. 2001;18:169-75.

8. Nagamatsu Y, Shima I, Yamana H, Fujita H, Shirouzu K, Ishitake T. Preoperative evaluation of cardiopulmonary reserve with the use of expired gas analysis during exercise testing in patients with squamous cell carcinoma of the thoracic esophagus. $J$ Thorac Cardiovasc Surg. 2001;121:1064-8.

9. Forshaw MJ, Strauss DC, Davies AR, et al. Is cardiopulmonary exercise testing a useful test before esophagectomy? Ann Thorac Surg. 2008;85:294-9.

10. Moyes LH, McCaffer CJ, Carter RC, Fullarton GM, Mackay CK, Forshaw MJ. Cardiopulmonary exercise testing as a predictor of complications in oesophagogastric cancer surgery. Ann $R$ Coll Surg Engl. 2013;95:125-30.

11. Sinclair RCF, Phillips AW, Navidi M, Griffin SM, Snowden CP. Preoperative variables including fitness associated with complications after oesophagectomy. Anaesthesia. 2017;72:1501-7.

12. Whibley J, Peters CJ, Halliday LJ, Chaudry AM, Allum WH. Poor performance in incremental shuttle walk and cardiopulmonary exercise testing predicts poor overall survival for patients undergoing esophago-gastric resection. Eur J Surg Oncol. 2018;44:594-9.

13. Drummond RJ, Vass D, Wadhawan $\mathrm{H}$, et al. Routine pre- and post-neoadjuvant chemotherapy fitness testing is not indicated for oesophagogastric cancer surgery. Ann $R$ Coll Surg Engl. 2018;100:515-9.

14. Thomson IG, Wallen MP, Hall A, et al. Neoadjuvant therapy reduces cardiopulmunary function in patients undegoing oesophagectomy. Int J Surg. 2018;53:86-92.

15. Benington S, Bryan A, Milne O, Alkhaffaf B. CPET and cardioesophagectomy: a single-centre 10-year experience. Eur $J$ Surg Oncol. 2019;45:2451-6.

16. Patel N, Powell AG, Wheat JR, et al. Cardiopulmonary fitness predicts postoperative major morbidity after esophagectomy for patients with cancer. Physiol Rep. 2019;7:e14174.

17. Lam S, Alexandre L, Hardwick G, Hart AR. The association between preoperative cardiopulmonary exercise-test variables and short-term morbidity after esophagectomy: a hospital-based cohort study. Surgery. 2019;166:28-33.

18. Sinclair R, Navidi M, Griffin SM, Sumpter K. The impact of neoadjuvant chemotherapy on cardiopulmonary physical fitness in gastro-oesophageal adenocarcinoma. Ann $R$ Coll Surg Engl. 2016;98:396-400.

19. Weisman I. ATS/ACCP Statement on Cardiopulmonary exercise testing. Am J Respir Crit Care Med. 2003;167:211-77.

20. Cunningham D, Allum WH, Stenning SP, et al. Perioperative chemotherapy versus surgery alone for resectable gastroesophageal cancer. N Engl J Med. 2006;355:11-20.
21. van Hagen P, Hulshof MCCM, van Lanschot JJB, et al. Preoperative chemoradiotherapy for esophageal or junctional cancer. $N$ Engl J Med. 2012;366:2074-84.

22. Charlson ME, Pompei P, Ales KL, MacKenzie CR. A new method of classifying prognostic comorbidity in longitudinal studies: development and validation. $J$ Chronic Dis. 1987;40:373-83.

23. Quan H, Li B, Couris CM, et al. Updating and validating the Charlson Comorbidity Index and score for risk adjustment in hospital discharge abstracts using data from 6 countries. Am J Epidemiol. 2011;173:676-82.

24. Phillips AW, Dent B, Navidi M, Immanuel A, Griffin SM. Trainee involvement in Ivor Lewis esophagectomy does not negatively impact outcomes. Ann Surg. 2018;267:94-8.

25. Beaver WL, Wasserman K, Whipp BJ. A new method for detecting anaerobic threshold by gas exchange. J Appl Physiol. 1986;60:2020-7.

26. Bard RL, Gillespie BW, Clarke NS, Egan TG, Nicklas JM. Determining the best ventilatory efficiency measure to predict mortality in patients with heart failure. $J$ Heart Lung Transplant. 2006;25:589-95.

27. Brunelli A, Belardinelli R, Pompili C, et al. Minute ventilationto-carbon dioxide output (VE/VCO2) slope is the strongest predictor of respiratory complications and death after pulmonary resection. Ann Thorac Surg. 2012;93:1802-6.

28. Barakat HM, Shahin Y, McCollum PT, Chetter IC. Prediction of organ-specific complications following abdominal aortic aneurysm repair using cardiopulmonary exercise testing. Anaesthesia. 2015;70:679-85.

29. Wilson RJT, Yates DRA, Walkington JP, Davies SJ. Ventilatory inefficiency adversely affects outcomes and longer-term survival after planned colorectal cancer surgery. $\mathrm{Br} J$ Anaesth. 2019;123:238-45.

30. Lindner K, Fritz M, Haane C, Senninger N, Palmes D, Hummel R. Postoperative complications do not affect long-term outcome in esophageal cancer patients. World J Surg. 2014;38:2652-61.

31. Xia BT, Rosato EL, Chojnacki KA, Crawford AG, Weksler B, Berger AC. Major perioperative morbidity does not affect longterm survival in patients undergoing esophagectomy for cancer of the esophagus or gastroesophageal junction. World J Surg. 2013;37:408-15.

32. Rutegård M, Lagergren P, Rouvelas I, Mason R, Lagergren J. Surgical complications and long-term survival after esophagectomy for cancer in a nationwide Swedish cohort study. Eur J Surg Oncol. 2012;38:555-61.

33. Jack S, West MA, Raw D, et al. The effect of neoadjuvant chemotherapy on physical fitness and survival in patients undergoing oesophagogastric cancer surgery. Eur J Surg Oncol. 2014;40:1313-20.

34. Altman DG, Royston P. The cost of dichotomising continuous variables. BMJ. 2006;332:1080.

35. Navidi M, Phillips AW, Griffin SM, et al. Cardiopulmonary fitness before and after neoadjuvant chemotherapy in patients with oesophagogastric cancer. Br J Surg. 2018;105:900-6.

Publisher's Note Springer Nature remains neutral with regard to jurisdictional claims in published maps and institutional affiliations. 